\title{
Technology-assisted foreign language learning (TALL) in the digital age
}

\author{
Anna Melkonyan ${ }^{1 *}$, and Armine Matevosyan ${ }^{2}$ \\ ${ }^{1}$ Moscow State Pedagogical University, Malaya Pirogovskaya Str., Moscow, 119991, \\ Russia Federation \\ ${ }^{2}$ Yerevan State University, Alex Manoogian st.,1 Yerevan 375049, Armenia
}

\begin{abstract}
The article goes along the lines of language learning in the digital age. Technology and the advancement of digital media not only have the potential to change the way we learn languages, but also the way foreign language teachers learn to teach. Managing learning platforms, using learning software and educational apps effectively, designing complex web -based tasks are just a few examples of digital media use in the foreign language instruction of today's schools. The article aims at showing of what types of skills and knowledge language teachers need to become digitally literate. Also we will focus on some challenges that an educator faces while teaching foreign language in the digital age.
\end{abstract}

\section{Introduction}

The rapid development of new technology and its worldwide application in education calls for innovative methods and approaches in teaching andlearning language in the digital age. The role of technology in the learning process offers wide opportunities to satisfy needs of students. Technology is changing the way language is taught and learned as well as our perceptions and conceptual understandings.

Increased usage of technology provides opportunities for multiple learning styles, and multiple modes of communication, interaction, and understanding. Research reveals that students exposed to multimedia materials are more apt to stop, reflect and edit their materials (Nutta, 2002). Innovative digital devices and platforms are enhancing foreign language teaching and learning in classrooms as well as creating new spaces inside and outside of the classroom.

Thus, for the foreign language teacher it is of paramount importance to implement digital tools which will enhance students' learning experience, expand their technology infrastructure. To become more competent and digitally literate educators need to develop special knowledge, a set of skills and a positive attitude toward digital media use. Provided that teachers have skills and knowledge regarding technology use they still face the challenges of selecting appropriate content and tools for their teaching. The key for successful technology use lies in teacher education.

\footnotetext{
${ }^{*}$ Corresponding author: aa.melkonyan@mpgu.su
} 


\section{Digital tools in the academic environment}

There are various technological opportunities which can be implemented by teachers. They should be carefully chosen in learning.

The Smartboard, an interactive whiteboard, motivates students' learning through interaction and promotes willingness to engage in classrooms. Its interactive projection display creates scenarios for language learning (Saine, 2012). Digital markers allow multiple learners to collaborate during storytelling. Notes on the smartboard can be saved on computer in digital format.

Content management systems (CMS) such as Moodle, Blackboard, E-learning, Brain Honey are widely utilized for middle school up to university language courses. These CMSs extend learning time and allow students to organize their assignments and track learning goals flexibly outside of class(e.g., taking onlinequizzes, using discussion boards, journals, andaudio-visual-textmaterials). Moreover, these CMSs allow students touse laptop and smart phone to access course syllabi, calendars, discussion board, and their grade book anywhere and anytime (Wang, 2012).

Mobile devices make language learning portable. Online dictionaries (e.g.,Pleco, Power Word) allow students to hear how the word is pronounced, see animation of how it is written, read examples of how it is used in sentences, as well as watch videos of how it is used in real life situations.

Language cellphone games (e.g., Chinese Skill) enable students to learn vocabulary, pronunciation and sentences, and entertain thelearning experience. Through smart phone text message polls and mobile voting, instructors can engage studentsin sharingtheir opinions about topics, quickly assess students' learning, and display percentage results on the screen for immediate feedback. With mobile voting, students can find out whether they answered the question correctly and the teachercan also review global classroom student performance results.

Social media (e.g., Facebook, Twitter, LinkedIn), blogs, video-sharing websites and website builders enable students to absorb vast audio-visual information as well as display their creative work. The video chat and text chat function allows foreign language learners to partner with native speakers outside the country and practice speaking online. Wireless internet and smart phone camera also allows learners to stream video images.

Website content builders such as Weebly, Worldpress allow instructors and students to easily develop websites without programming skills. These types of digital software devices and apps also permit individualized and differentiated language instruction at the student's pace as well as in cooperative and collaborative formats, especially in mixed-level FL classrooms.

In the digital age, geographic distances, which were once barriers for face-to-face foreign language classes, can be bridged through online and distance learning. Teachers, students, and technology support staff can attend the sameclass without being at the same geographic location.

Video conferencing software (Adobe Connect, Zoom, Skype, Microsoft teams) have revolutionized foreign language teaching and learning. Video conferencing provides virtual platforms that can be utilized to practice and reinforce what islearned collaboratively in the classroom. It permits authentic tandem language learning with peers and overcomes the limitation of the traditional foreign language classroom - the ability to invite learners unable to attend face-to-face learning class (Hubbard, 2009; Zarotsky \& Jaresko, 2000). As we see, videoconferencing expands the scope of cross-language communication and human interaction as well as increases the speed of language transfer (e.g. novel word and expression development, language borrowing, and gesture cognizance). These immediate 
technological connections promote classroom diversity and offer new approaches for working with diverse global learners.

Massive Open Online Courses (MOOCs) have been developed for network learning associated with self-regulated study, peer sharing, and collaboration (McAuley, Stewart, Siemens \& Cormier, 2010). MOOCs allow unlimited users to get free access to the course online to support study specific topics as well as "offer extensive diversity, connectivity and opportunities for sharing knowledge" (Mackness, Mak, \& Williams, 2010, p. 266).

From the above mentioned we apparently see that in order to facilitate all students' foreign language learning in the digital age, the trend of new technology development in the $21 \mathrm{st}$ century requires educators to befluent in the use of technology. However they should also be aware of the knowledge and background of their learners (Wang, 2012; Wang, 2015). Technology should be a tool to enhance not a means to enforce how students learn.

When language classes become global through Internet technologies, course designers and instructors need to take accessibility factors in curricular design. Online technology has the potential to provide equitable access to language, heritage language, and dual language for remote and disadvantaged learners; access to learnersin remote places via wireless network or Internetnarrows the dividebetween those in privileged circumstances and others from disadvantaged situations. The mobile phone is the tool that is providing more access to people and information than other sources, such as computers (Blinn-Pike, 2009). Thus, a goal for educators would be to utilize this approach in formal face-to-face and online learning situations since the phone is generally the most accessible and affordable device for language learners. Informally, the cell phone connects learners with one another to maintain heritage language or learn others through free apps such as Skype.

Congruently, educators need to consider students' prior linguistic and cultural knowledge as potential and free resources for language maintenance and authentic interaction, which can supplement formal foreign language learning in and outside of the classroom (Young \& Helot, 2003; Winstead, 2013).

High demand for not only linguistic but cultural knowledge is being recognized in corporate industry (Grosse, 2004, 2010; Kramsch, 2005). Foreign language educators, correspondingly, need to recognize diverse students'prior language and cultural background knowledge as potential resources for language opportunities (DerderianAghajanian \& Wang, 2012). Technology enhanced environments have expanded the way language learners background can be utilized as potential resources in technology-enhanced learning environments. Educators can create online liaisons, utilizing mobile devices, between theseindividuals to enhance language exchange. Providing native language speakers with online communicative practice leads to more accessible and more equitable opportunities for learnerswho are socioeconomically disadvantaged but want to learn a foreign language with a native speaker. Online technology provides tandem formats for dual and plurilingual language exchange and provides opportunities for authentic interactionamong native speakers.

After celebrating the surprises that technologies have brought to human society in the $21^{\text {st }}$ century, educators and researchers should look back at the glory of the less digital side of human society. When humans are toobusy learning new things, there is little time to think about the human aspects that may disappear in the digital age. Without reflection upon how digital technologies reshape human society it is difficult to understand how aspects of language and culture might be lost or replaced

Thus New digital culture and language can influence face-to-face as well as online social interaction. Although children who have broad accessibility to technology (e.g., Warcraft, Facebook, YouTube, Youku) may spend most time socializing online instead of in real life (Gee \& Hayes, 2011). From teenagers to adult couples, mobile devices allow users to enjoy digital intimacy near or far. Through the Internet, people may make friends globally with 
or without knowing the other party's identity. Technology allows shy learners to interact anonymously with humans. Social media may distance these users from family and friends. People from all cultural backgrounds may be fascinated by what innovative technology has brought to life yet may become bogged down in the ways digital culture overrides and sometimes replaces aspects of their traditional culture and socialization modes. How does technology impact language evolution?

There is one more negative aspect - The shaping power of technology on interrelation in human society deconstructs ourtraditionalcultural behaviors and interactions. Technology provides innovative means for communication and opportunities to mirror the cultural background of particular languages being learned. Translanguaging and code-switching languages have been utilized as a term to describe how speakers of two languages and bilinguals may insert words from two or more languages (Garcia \& Wei, 2014).

Currently, technologies are utilized as facilitators in various language learning classroom contexts . In the future, will technologies replace the human language instructor? Where does technology drive humans' role in a technology-dominant society? With more human labor being replaced by machines to manufacture products, to help customers check out in stores, robots to monitor phonecalls, software conducting translations, and virtual guides touring visitors at museums, concerns arise about how and where technology will drive the role of the human. This is a thing that worries us and we should always remember about a human factor in all these aspects.

\section{Digital Colonization: Replacement of Human Learning}

While technology has not replaced humans in language education, the next generation of technology is under research and has the potential to replace humaninstructors. With awareness and self-education in technology, some language educators may feel hesitant to adopt technology due to fear about being replaced by it. Schools and universities provide benign opportunities for technological professional development so that professors can convert their current on-campus courses into online formats. This reveals a new feature of technology-driven education. Developing an online language course requires a lot of expertise and effort in not just language but also technological know-how. The course might be equipped with vivid videos and animations, free resources for self-exploratory education and other engaging technologies. Once the course is developed, it requires less from the instructor who may only be needed to facilitate and manage the course when technologies fall short of human intelligence or aspects of the program become outdated, or where human technologies.

Since well-developed courses can be shared as well as assigned to those that have less experience (e.g., teaching assistants), and the university's ownership of intellectual property of the course has the potential to causebarriers in the language instructor or language developer's job relocation, those who invest huge amounts of time and knowledge to develop courses may begin to feel used and under paid for theirefforts. Course developers' intellectual rights are not addressed or protected and they may be considered obsolete once the course and format is in place, losing their position and the course they built. Technology course building benefits institutions in a transition from education to business by reducing the budget of human labor. Since technology can be duplicated at low cost, time will only tell how positions might be eliminated.

The tech-industry drives education towardsanunclearfuture. Artificial intelligence advances reveal, for the first time, how an AI machine can compete and even beat a human at a Go board game (Chappell, 2016; Shang-hun \& Mar- koff, 2016) reflective of notions of more advanced robotic abilities as similarly suggested in the movie Terminator. While it takes humans many years to learn alanguage, it may take a robot justseconds 
to be programmed or reprogrammed.The learning speed of humansmayfall behind that of future technologies. Robots are designed with efficiency, fastspeed,and duration and even attractive appearance to overcome human shortcomings (Goodrich \& Schultz, 2007; Russell \& Norvig, 1995). From a robotic perspective, human time spent on rest, love, encouragement, and entertainment may be viewed as a waste or flaw in design. The danger of this machinery mindset is that society may become de-humanized when humans are expected to function efficiently as robots while robots function as autonomously and intelligently as humans. Should human and computer robots become rivals, a widening divide will emerge between TALL and human-facilitated language learning and technologydominated instruction. The potential human-AI conflict is just a reflection of human society conflict. If humans cannot overcome their own shortcomings as a society, humans may carry the same mistakes. When tension regarding resources and intelligence escalate, humans may lose more than they wagered.

Standing the intersection of human language history, we should give language teachers credit for their time, effort, patience, care, love, and other emotional and intellectual investment in helping those who are disabled, newcomers, or justordinary learners become who they did not dream to become. Those educators are the first people whowelcome disadvantaged children such as refugees. Their effort to make those children feel home in a new community is invaluable, and, most importantly, human. Thesehuman aspectsare what advanced technologycan hardly surpass. Eye-contact, asmile, face-toface interaction, these simple moments bind the two individuals emotionally and nonverbally. The uniqueness of feeling cared and loved cannot be duplicated. This is the authenticity of human society as well as the originality of language learning.

\section{Conclusion}

Thus, technologies can have the potential to promote human gain. The following above mentioned examples reveal how language teaching and learning supported by technology can provide authentic and real-time human- to-human scenarios that benefit and support language practice, development and acquisition. We just need to be mindful and not blind to the potential of technology to provide benefits to human learning, language preservation and maintenance. And, most of all, that we are still able toprovidea humantouch. To gain success in foreign language teaching through educators we need to implement various technological tools in the learning process. It will facilitate all students' foreign language learning in the digital age.

\section{Acknowledgements}

This paper was financially supported by the Russian Foundation for Basic Research, grant № 20-012-22046.

\section{References}

1. J. Nutta, C. Feyten, A. Norwood, J. Meros, M. Yoshii, Exploring new frontiers: What do computers contribute to teaching foreign languages in elementary school? Foreign Language Annals (2002)

2. P.Saine, iPods, iPads, and the SMARTBoard: Transforming literacy instruction and student learning. New England Reading Association Journal (2012) 
3. C.Wang, Pre-service teachers' perceptions of learning a foreign language online: Preparing teachers to work with linguistic, cultural, and technological diversity. International Journal of Computer- Assisted Language Learning and Teaching (2012)

4.P. Hubbard, Computer Assisted Language Learning: Vol. 1-4. (Critical Concepts in Linguistics Series). London, UK:Routledge (2009)

5. V. Zarotsky, \& G.Jaresko, Technologyineducation-Wheredowe gofromhere? Journal of Pharmacy Practice (2000)

6. A.McAuley, B. Stewart, G.Siemens, \& D. Cormier, The MOOC model for digital practice (2010)

7. J. Mackness, S. Mak, \& R. Williams, The ideals and reality of participating in a MOOC. In L. Dirckinck-Holmfeld, V.Hodgson, C. Jones, M. DeLaat, D. McConnell, \& T. Ryberg(Eds.), Proceedings of the 7th International Conference on Networked Learning, pp. 266-275 (University of Lancaster Press, Lancaster, UK, 2010)

8. C.Wang, From preservice to inservice: Can practicing foreign language learning online help teachers transfer linguistic, cultural, and technological awareness into teaching English Language Learners? International Journal of Computer-Assisted Language Learning and Teaching,5(2) (2015)

9. L. Blinn-Pike, Technology and the family: An overview from the 1980s to the present. Marriage \& Family Review, 45(6-8), 567-575 (2009)

10.A. Young, C.\&Helot, Language awarenessand/orlanguagelearning in Frenchprimary schools today. Language Awareness, 12 (3 \& 4), 234-246 (2003)

11. L.Winstead, Apprehension and motivation among adolescent dual language peers: Perceptions and awareness about self-directed teaching and learning. Language and Education (2013)

12. C.U. Grosse, The competitive advantage of foreign languages and cultural knowledge. Modern Language Journal (2004)

13. C.U. Grosse, Corporate recruiter demand for foreign language and cultural knowledge, Global Business Languages (2010)

14.C. Kramsch, Post 9/11: Foreign languages between knowledge and power. Applied Linguistics, 26(4), 545-567 (2005)

15. A. Derderian-Aghajanian, \& C.C.Wang, How culture affects on English Language Learners' (ELL's)outcomes, withChineseand Middle Eastern immigrant students. International Journal of Business and Social Science (2012)

16. J.P.Gee, E.R. Hayes, Language and learning in the digital age (Routledge, New York, NY, 2011) 
17. O. García, L.Wei, Translanguaging: Language, bilingualism and education (Palgrave Macmillan, New York, NY, 2014)

18. B.Chappell, A.I. program from Google beats human world champ in game of Go. NPR: The Two-Way (2016). Retrieved from http://www.npr.org/sections/thetwoway/2016/03/09/469788814/ ai-program-from-google-beats-human-world-champ-ingame-of-go

19. C.Sang-Hun, \& J. Markoff, Master of Go board game is walloped by Google computer program. The New York Times (2016). Retrieved from http://www.nytimes.com/2016/03/10/world/asia/ google-alphago-lee-se-dol.html?_r=0

20. M.A.Goodrich, \& A.C. Schultz, Human-robot interaction: A survey. Foundations and Trends in Human-Computer Interaction, 1 (3), 203-275 (2007)

21. S.Russell, \& P. Norvig, Artificial Intelligence: A Modern Approach. New Jersey: Englewood Cliff (1995) 